Article

\title{
Holistic Management and Adaptive Grazing: A Trainers' View
}

\author{
Carolyn Mann and Kate Sherren * \\ School for Resource and Environmental Studies, Dalhousie University, Halifax, NS B3H 4R2, Canada; \\ carolyn.mann@dal.ca \\ * Correspondence: kate.sherren@dal.ca; Tel.: +1-902-494-1359
}

Received: 22 March 2018; Accepted: 31 May 2018; Published: 2 June 2018

\begin{abstract}
Holistic Management (HM) is a grazing practice that typically uses high-intensity rotation of animals through many paddocks, continually adapted through planning and monitoring. Despite widespread disagreement about the environmental and production benefits of HM, researchers from both sides of that debate seem to agree that its emphasis on goal-setting, complexity, adaptivity and strategic decision-making are valuable. These ideas are shared by systems thinking, which has long been foundational in agroecology and recognized as a valuable tool for dealing with agricultural complexity. The transmission of such skills is thus important to understand. Here, twenty-five Canadian and American adaptive grazing trainers were interviewed to learn more about how they teach such systems thinking, and how they reflect upon their trainees as learners and potential adopters. Every trainer considered decision-making to be a major component of their lessons. That training was described as tackling both the "paradigm" level—changing the way participants see the world, themselves or their farm —and the "concept/skill" level. Paradigm shifts were perceived as the biggest challenge for participants. Trainers had difficulty estimating adoption rates because there was little consensus on what constituted an HM-practitioner: to what level must one adopt the practices? We conclude that: (1) trainers' emphasis on paradigms and decision-making confirms that HM is systems thinking in practice; (2) the planning and decision-making components of HM are distinct from the grazing methods; and (3) HM is a fluid and heterogeneous concept that is difficult to define and evaluate.
\end{abstract}

Keywords: Holistic management; adaptive grazing; agroecology; systems thinking; social-ecological system; complex system

\section{Introduction}

The challenges facing modern agriculture are more daunting than ever before. Farming has become not only a leading driver of much environmental degradation, but is also uniquely vulnerable to its effects. In 2010, agriculture was responsible for $11.2 \pm 0.4 \%$ of global greenhouse gas emissions, rising at about $1 \%$ per year [1], and yet modelling shows that climate change will deteriorate growing conditions in most of the world through drier, hotter and more variable conditions [2,3]. Land degradation and desertification is estimated by the UN Convention to Combat Desertification (UNCCD) to affect one-third of our planet's land [4] and global response is urgently needed [5]. This is linked to global trends in soil degradation, including soil carbon loss, nutrient leaching, salinization, acid deposition, heavy metal contamination, erosion, compaction and compromised water storage capacity [6]. Agriculture accounts for $80 \%$ of global freshwater use, at such high rates that water tables are almost universally dropping and many large rivers now regularly run dry [7]. On top of these complexities, our global food system will need to feed an estimated 9 billion people by 2050 
which, when combined with changing diets, has led some to estimate food supply must increase by $70-100 \%$ [8].

Occupying about $25 \%$ of global land and situated largely on drylands, grazing makes up a significant proportion of agricultural activities [9]. Many of the environmental impacts attributed to agriculture are particularly linked to animal production. Overgrazing and mismanaged grazing cause desertification in drylands, ecosystem change by altered plant community response, and deforestation [9]. The widely-cited United Nations Food and Agriculture Organization (FAO) report, Livestock's Long Shadow, attributed 18\% of global GHG emissions to livestock [10], but others have argued that uncounted or overlooked contributions such as unreported livestock production may contribute significantly more [11]. Although it is difficult to untangle the effects of grazing from other livestock production methods like concentrated animal feeding operations [12], the numbers are nonetheless staggering. Nascent carbon markets have inspired new research into the possibility that grazing lands managed adaptively may sequester carbon.

In the 1980s, biologist and livestock farmer Allan Savory developed Holistic Management (HM), a grazing method which he recently claimed will reverse desertification and halt climate change while simultaneously reducing poverty and violence [13]. Two major international organisations have grown out of Savory's work: the not-for-profit Holistic Management International (HMI) provides HM education and training, and the for-profit Savory Institute has developed a global network of "hubs" to demonstrate and encourage HM practices. Many similar grazing strategies exist under different names (see Box 1), which we collectively term adaptive grazing for this study. HM has a dual nature as conceived by Savory, comprising the grazing method and the decision-making framework. The method involves adaptive, high-intensity rotation of animals through many paddocks, and it has been embraced by some but has met with criticism from the academic community [14-18]. As a decision-making framework, however, the HM method's biggest acknowledged contribution to the grazing world is arguably its emphasis on adaptivity, strategic decision-making, goal-setting and complexity [19].

Box 1. Alternate terms for Holistic Management or adaptive grazing, which were used as Google search criteria to find trainers.

Holistic Grazing
Rapid Rotation Grazing
Time-Controlled Grazing
Planned Grazing
Prescribed Grazing
Management-Intensive Grazing
Rest-Rotation Grazing
Deferred Rotation Grazing
High Frequency-Short Duration Grazing
Season-Long Grazing
Intensive Short-Duration Grazing
Adaptive Multi-Paddock Grazing
Savory Grazing
Cell Grazing
Swath Grazing
Managed Grazing
Grazing Management
Adaptive Grazing
High-Intensity Short Duration Grazing
Controlled Grazing

The decision-making principles advanced by HM are also shared by the discipline of systems thinking, which has been lauded by researchers for decades as a useful conceptual tool for improving farmers' responses to problems in an increasingly complex world [20-24]. Because novice systems 
thinkers require training to successfully use systems thinking tools, the way in which these concepts are transmitted to farm decision-makers is critically important [25]. However, despite recommendations for controlled pre- and post-testing to assess the effectiveness of systems thinking interventions [26], twenty years later, there is still no consensus on the best tools for applying systems thinking or the best ways to teach it.

As a real-world application of systems thinking, adaptive grazing may be a valuable tool for improving farmers' decision-making capacities. The purpose of this project is to describe adaptive grazing training in Canada and the United States, and to learn more about how adaptive grazing trainers see their work and their trainees. We define adaptive grazing trainers as anyone providing courses, lessons or training on HM principles or practices, either related directly to grazing or more widely to farming and landscape management. This broad view is necessary because the trainers themselves are diverse: they have a wide range of backgrounds and play different roles in the HM community depending on their affiliations. Twenty-five adaptive grazing trainers were interviewed about their training programs and the people that take their training to explore: (1) what HM trainers profess to teach and why; (2) who they train and why the trainers think those trainees are attracted to HM training; and (3) what HM trainers know about trainee adoption of adaptive grazing.

\section{Background}

Some foundation is useful on the nexus between adaptive grazing and systems thinking. First, we describe Holistic Management and outline the current adaptive grazing debate; second, we briefly outline the concepts inherent to systems thinking and some of its applications in agroecology; and finally, we draw links between adaptive grazing concepts and systems thinking.

\subsection{Holistic Management Principles, Practices and Debates}

$\mathrm{HM}$ is based on "Four Key Insights" drawn from Savory's own observations and the work of others, such as André Voisin's Rational Grazing [27]. These insights are: (1) the world functions in wholes, and should be managed as such; (2) environments exist on a scale of brittleness, from very brittle (dry, with uneven precipitation throughout the year) to non-brittle (humid year-round); (3) brittle environments evolved with large herds of grazing animals concentrated and forced to move by pack-hunting predators, which maintains and improves the health of the land; and (4) overgrazing is not related to the number of animals, as traditionally thought, but to the amount of time when the land is exposed to animals and the time given for recovery [28]. Based on these insights, Savory argues that grasslands require herbivory to remain productive, that is, individual grasses will senesce and die if left ungrazed, and grasslands will deteriorate if left to rest [28].

Savory does not provide specific prescriptions for animal density or timing of rotation but rather guidelines for adaptive decision-making after a structured process of goal setting and an audit of farm resources. In general, HM advocates for doubling or tripling the number of stock (depending on the starting stocking rate), which are then quickly rotated between many pastures to which the animals will not return until the plants have had sufficient recovery time, thereby mimicking a wild grazing herd [28]. This may mean that each paddock is grazed only once every few months or once per year. By emphasizing holism and disregarding experimental science, Savory has become something of a grazing anarchist: he portrays his ideas as an art or even a religion which cannot be understood through the lens of reductionist science [29]. This "religious zeal" is reflected in the "chapter and verse" language sometimes used by HM practitioners in interviews [17].

Experimental science typically reveals neutral or mixed results from HM grazing [17]. An early review found no increases from HM in forage production, plant community response, range condition, harvest efficiency, livestock productivity or farmer income [30]. Many of Savory's underlying ecological claims are controversial and not generalizable across all ecosystems: not all drylands evolved with large grazing herds; grasses do not necessarily depend on grazing for their own survival; grasslands may or may not improve if grazing animals are excluded; and hoof action—one of Savory's favourite 
tools-does not always improve soil health, but can destroy biological soil crusts, increasing erosion and compaction [16]. Savory's claims that stocking rate is not an important determinant of plant community, and that grazing systems can universally sequester carbon, have also been challenged and evidence raised to the contrary [16,30]. Moreover, continuous grazing is generally found to equal or outperform rotational grazing in terms of plant and animal production, meaning that a range of viable grazing strategies likely exist [14,31]. Meta-analysis suggests that HM has no consistent positive effects on plant basal cover, biomass or animal production when compared to season-long continuous grazing, and may function better in high-moisture environments than the "brittle" ones for which Savory advocates it [32]. In fact, operation type may have a stronger effect on rangeland plant composition than grazing management strategy or planning style [31]. Adaptive rotation sometimes improves aboveground biomass and yield, but inappropriate combinations of adaptations-i.e., poor decision-making - deteriorates rangeland further than non-adaptive strategies [33]. A minimum of experimental studies reveals positive effects of high-intensity rotational grazing [14].

However, HM practitioners themselves are avid proponents, and their positive feedback is widely documented by social scientists and whole-farm studies [14,17]. Some of the benefits HM producers or researchers report in various regions include: biodiversity, landscape heterogeneity, quality of life, drought resilience, adaptive capacity, and social capital [34-37]. Experimental studies have been criticized for excluding the farmer and thus the goals for which farmers are managing [17], on the assumption that farmers' management decisions solely consider productivity [38]. In fact, farmers consider a wide range of variables when making decisions, including social variables (goals, risk tolerance, willingness to experiment, information networks, lifestyle, independence), ranch-specific variables (size and type of operation), and ecological and policy considerations [38-40]. Because adaptive decision-making is a central tenet of $\mathrm{HM}$, including the farmer is critical for $\mathrm{HM}$ research $[28,41]$. Some experimental scientists have also acknowledged these weaknesses, calling on researchers to better distinguish between simple and complex problems, to monitor outcomes more consistently, and to integrate social and biophysical research more explicitly [19].

\subsection{Systems Thinking and Agroecology}

Systems thinking is "the ability to represent and assess dynamic complexity" [42] (p. 2). Its tools and concepts are useful to farmers because agriculture itself is a complex series of nested systems facing quickly changing conditions and demands [20,21]. Because farmers prefer to avoid uncertainty and simplify decision-making when possible, systems thinking tools can be useful for communication and learning [43]. To adopt systems thinking in agriculture, however, means that everyone from researchers to practitioners must question their own beliefs, think across boundaries, and embrace complexity and chaos [20]. Within this paradigmatic shift—-to change our deepest, unspoken beliefs about the world-lies both the biggest challenge and the greatest strength of systems thinking [44]. $\mathrm{HM}$ or adaptive grazing trainers, who teach these systems concepts through their training programs, therefore represent an important example of the transmission of such tools to local decision-makers.

The many elements and relationships of complex systems make comprehension impossible in simple, logical ways [45]. Systems are intricately connected and nested within one another [46]. By incorporating concepts like complexity, emergent properties, tipping points, and feedback loops, the holistic worldview argues that everything is interconnected; even boundaries between systems are artefacts of human perception [47]. High-functioning systems are often resilient, that is, they have a capacity to bounce back or recover after a disturbance, and are often highly dynamic [44]. Emergent properties-phenomena that are not predictable from known components or relationships-may result in massive system disruption, making predictions difficult [45]. Systems have tipping points or thresholds toward which a system may slowly move until passing a certain point, after which the system shifts quickly and unpredictably [45]. Feedback loops may exacerbate system change through a cyclical series of events which may be self-reinforcing or self-damping [45]. Dealing with this complexity requires "strategies" rather than "solutions" [46]. 
Some applications of systems thinking, such as agroecology, have been very successful in recognizing agriculture's "involved hugeness" in our world [48] (p. 280). Having stratified itself into a science, a movement and a practice, agroecology is conducted at multiple scales from field-level to global food system [49]. Its combined emphasis of social, environmental, economic and production considerations make it a notable "transdiscipline" within systems thinking [50]. Other applications of systems thinking in agriculture include farming systems research (FSR), systems agriculture [20,46], and agricultural innovation systems [51,52]. Practical applications include, for example, permaculture, an interdisciplinary design system that relies on natural patterns to create sustainable food and community systems, and its predecessor keyline design, which integrates specialized contour design and cultivation techniques to retain water and build topsoil [53]. The following section explores how $\mathrm{HM}$ and adaptive grazing also share many of these systems thinking ideas.

\subsection{Adaptive Grazing as Systems Thinking}

Rather than engage further with the HM debate described in Section 2.1, or more theoretical debates such as ecofeminist critiques of holism [54], we seek to use HM and adaptive grazing as examples of system and agroecological thinking. It has been suggested that HM's greatest contribution to the grazing world is its emphasis on systems thinking ideas [19,55]; indeed, this may be the only point on which researchers from both sides of the spectrum can agree [14]. Some consider HM to be an "agroecological intensification" system that integrates ecological and biodiversity goals with increasing productivity and reduced reliance on external inputs [56], and, similar to agroecology, HM shares many traits with systems thinking. In particular, adaptive grazing incorporates an inherent interdisciplinarity that integrates social, environmental and economic perspectives; an application of specific systems thinking concepts including holism, feedback loops, and complexity; an emphasis on adaptivity in the face of complexity; and the use of specific tools advocated for by systems researchers, such as participatory landscape maps and comparative matrices.

Adaptive grazing is meant to give managers the ability to consider economic, social and environmental realities when making decisions so that every action moves toward long-term goals and sustainability [28]. HM outlines a set of general questions to ensure every action aligns with the triple bottom line-people, planet, and profits. These include: Would this action create friction between us and the people whose support we rely on? Does this action lead toward a sustainable resource base? Which action contributes the most to covering overhead costs?

Although HM was developed in grazing systems, which continues to be its main application, Savory argues that HM can be applied to any "whole" under management [28]. Holism is a defining principle of HM; as Savory notes, "one has to accept that, in reality, there are no boundaries, only wholes within wholes in a variety of patterns" [28] (p. 29). The first step in adopting HM is to define the whole under management, that is, all the people and their skills, the resource base and inventory available, and the sources of income [28]. Next, practitioners define a "holistic context": the purpose of the whole under management, the desired quality of life, and the resource base that must be in place [28].

A second core tenet of HM is adaptivity-that is, nothing is strictly prescribed, but decisions are based on stated goals in combination with close observation of the soil, plants, water and animals. Savory differentiates between the complicated—things we make, such as technologies—and the complex systems that we manage, such as natural systems or human relationships [57]. The need for adaptivity comes from the inherent complexity and unpredictability of natural systems, because "in real life things seldom go smoothly" [28] (p. 485). Savory uses feedback-loop thinking to monitor and control outcomes: "The word plan becomes a twenty-four-letter word: plan-monitor-control-replan" (p. 484). He advocates for assuming every decision is the wrong one, and monitoring for any indication of things going awry, so that corrective actions can be taken immediately.

HM and adaptive grazing, with its emphasis on systems thinking concepts, may help farmers deal with complexity and improve decision-making skills. How these ideas and skills are transmitted 
to trainees becomes a very important question, one which we respond to by interviewing adaptive grazing trainers about their training.

\section{Materials and Methods}

We treat adaptive grazing as an applied example of systems thinking in agriculture, and focus on how these systems concepts are seen by trainers, taught to farmers, and received by potential HM-practitioners. We interviewed 25 adaptive grazing trainers across Canada and the US, using methods reviewed and approved by the Research Ethics Board for Social Sciences and Humanities at Dalhousie University on 21 September 2017 (REB \# 2017-4298). As researchers we are interdisciplinary, with experience combining social science with natural and/or spatial science approaches on farming system research. Past work by KS with farmers using a range of grazing approaches in Australia has produced papers supportive of HM for drought resilience. As such, the trainers we approached for interviews would likely have perceived us as "friendly" researchers in this polarized space [17]. As we sought to describe only the adaptive grazing training phenomenon, rather than compare it with other methods, we consider our positionality to be of minimal impact.

HM trainers were identified through their association with an HM organisation-either Holistic Management International (HMI) or the Savory Institute—or through personal websites and producer magazines advertising adaptive grazing management training. Google searches for terms such as "Holistic Management", "holistic grazing" and "rapid rotation grazing" were used to identify trainers that were not associated with HM organisations (Box 1). Ninety-seven identified trainers were contacted by email or through the contact form on their website and invited to participate in a 20-30-min interview by phone or Skype. Thirty-four responded positively, but not all were able to be scheduled. Interviews with 25 trainers were conducted from October to November 2017.

All of our semi-structured interviews were audio-recorded and later transcribed, except for one interview in which notes were taken by hand and then sent to the participant to review. Coding and analysis were undertaken using QDA Miner Lite. We used memos to document ideas, connections, references, comments and questions throughout the data collection and analysis stages [58]. A "conventional" content analysis approach was used for transcript analysis, that is, themes, topics and codes were developed from the data themselves rather than applying pre-existing theory or ideas [59]. First, each transcript was divided into sections based on groups of similar questions (Table 1). Each section was read through and major themes or topics were noted, which were then used to develop codes. Transcripts were then read through in depth and coded, with a final read of the transcripts used to check the coding. This process sometimes resulted in codes being re-developed or rearranged if they did not adequately represent the participants' responses overall. Following initial analysis, we used a "member check" to improve the validity of our results by sending an initial report of our findings to the 25 participants and soliciting comments or questions. We received 12 affirming responses about our interpretation, including only one suggested clarification, which we incorporated into our findings. Results are provided both quantitatively, using the number of trainers discussing a code as a proxy for its importance [60], enriched with indicative quotes attributed to codes that include the trainer's country (US or CA) and the interview number.

Table 1. Breakdown of key topics and related interview questions.

\begin{tabular}{cl}
\hline Section Title & \multicolumn{1}{c}{ Related Interview Questions } \\
\hline \multirow{2}{*}{ The trainers } & $\begin{array}{l}\text { How did you come to teach or mentor this approach? } \\
\text { How many people have you trained in the past? }\end{array}$ \\
\hline \multirow{2}{*}{ The training } & $\begin{array}{l}\text { What are the major topics /lessons of your grazing training? } \\
\text { What is the one key lesson that you hope all of your trainees grasp? } \\
\end{array}$ \\
& Do you consider your training to align with HM (as described by Allan Savory)? \\
\hline
\end{tabular}


Table 1. Cont.

\begin{tabular}{cl}
\hline Section Title & \multicolumn{1}{c}{ Related Interview Questions } \\
\hline & How would you describe the people that you usually train? \\
& Are they themselves ranchers? \\
The trainees & Are they typically men or women? \\
& How old are they? \\
& Are the trainees usually individuals, families, or teams? \\
& Why do people take the training? \\
\hline & Are the trainees typically familiar with holistic or adaptive concepts already? \\
& If so, what areas are they usually familiar with? \\
& What concepts are usually new to people? \\
& Do trainees ever struggle with the adaptive concepts you teach? \\
& If so, what concepts are most difficult for them to grasp? \\
& What concepts are the easiest for most people to grasp? \\
\hline & Do you keep track of your trainees after their time with you? \\
Adoption & If so, what kind of adoption rate do you observe? \\
& What do you think causes that adoption rate?
\end{tabular}

\section{Results}

\subsection{The Trainers}

Of the 25 participants, eight were Canadian and 17 American (five women, 20 men). These trainers operated in a wide range of ecosystems and often travelled widely to provide their training; these different ecosystems would affect management practices but do not seem to affect management principles. Some had been teaching for only two years, and others for decades: two estimated having taught fewer than 100 people; 15 estimated 100-1000 trainees; and six estimated training more than 1000 people. We did not explicitly ask why they taught adaptive grazing methods, but when asked how they came to teach it, many trainers (15) described a diverse background in sustainable agriculture or alternatives to conventional techniques, such as training in permaculture, keyline design, or a range of adaptive grazing methods, both HM and non-HM. Nine trainers had tried adaptive grazing on their own operations, and seven discussed being immediately drawn to it because it made sense to them. Four discussed teaching the methods to help fix issues in agriculture, both at the personal level-improving farm finances and farmers' quality of life-and at the system-level—addressing environmental issues in agriculture. We did not ask about the cost of their own training, or how they are compensated for offering it.

Seventeen trainers were formally aligned with the Savory Institute and/or HMI, yet of those four did not consider their training to align with Savory's HM because of differences in training style or a relaxation of what they described as Savory's stringent requirements. Of the eight trainers not aligned with HMI or the Savory Institute, two considered their training to align completely with HM principles, and the others considered their training to overlap in majority. Several trainers mentioned that they chose to participate in this study to advance pro-HM evidence in the academic literature, although we did not explicitly ask trainers about their motivations for participating.

\subsection{The Training}

Most trainers (70\%) said that their training included practical farming/grazing lessons as well as teaching a method or set of tools for decision-making; the remaining $30 \%$ focused on teaching primarily decision-making. The trainers saw the capacity to make new and better decisions as critical, and practical lessons were meant to inform better decision-making.

As trainers discussed the content of their instruction, it became clear that adaptive grazing training takes place at multiple conceptual levels, which here we divide into two categories: paradigm shifts, 
and concepts/skills. Concept/skill-level training focused on developing skills or knowledge that can be directly used or applied, whereas paradigm-level training addressed the way that trainees understand themselves, their operation or the world. Four paradigm themes were identified: holism, complexity, empowerment and mimicking nature (Figure 1). Only three trainers did not discuss training at the paradigm-level, one of whom was HM-aligned and two of whom were non-HM. For the majority, shifting paradigms was considered critically important for teaching trainees how to make better decisions. As described by one trainer:

"... what I believe determines what I do, what I do determines the result I get, and the reason I bring that up is because the biggest challenge of teaching anybody anything about grass is to shift the way they see the world" (US10)

The most commonly-discussed paradigm shift, holism, means recognizing a system's interconnectedness by considering social, economic and environmental factors and the relationships between them:

"understanding that everything is interconnected, that we can't just focus on one single goal unless we've done the deeper background work about ... how everything relates to everything else" (US04)

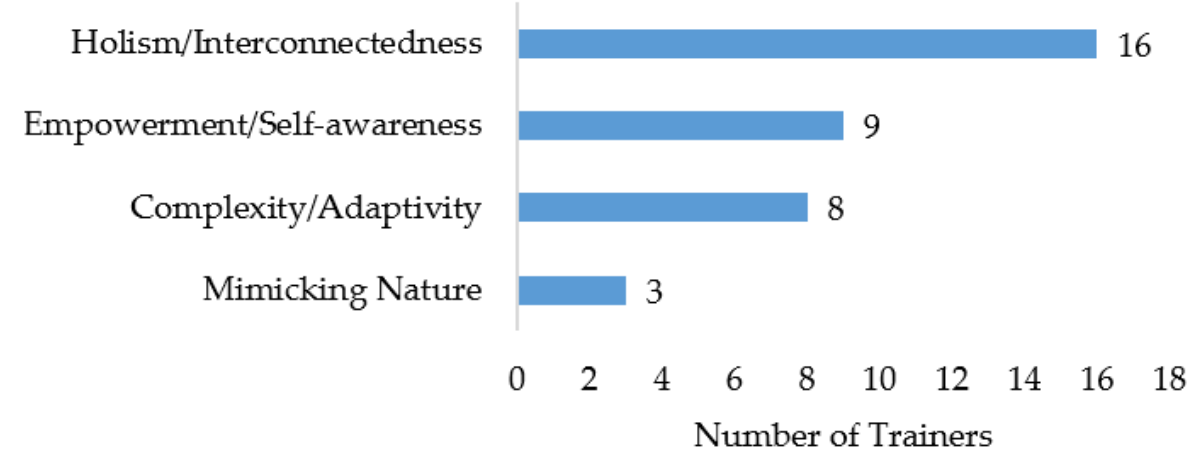

Figure 1. Key themes of adaptive grazing training at the paradigm-shift level.

Adaptivity to complexity, mentioned by eight trainers, was seen by them as a key part of being a farmer, but a skill that must be developed to inform good decisions:

"It's not a factory system, we always have to deal with natural challenges and biological challenges, and so the one thing that we want people to understand is that you, in order to be highly successful at farming and ranching, and highly profitable, then you must learn how to be adaptive in your approach, on a day to day basis, not prescriptive" (US09)

An important part of learning to be adaptive and make good decisions is feeling empowered to do so. Nine trainers spoke of the farmer as the expert on his or her own situation, having not only a right but a responsibility to make good decisions:

"That people have permission to make decisions. Permission to think ahead. That, that's an issue for some people, that they can actually look at things differently, that they can be different, without, without judgement" (US06)

"I consider myself not a teacher but a more knowledgeable other, and so the more knowledgeable other helps you to own that information. It's not only just my information, it's your information, that you own" (US01)

At the level of key concepts/skill the most important, as seen by trainers, was the farm goal, also termed the holistic context, holistic goal or mission statement, which is a long-range inclusive 
vision for the organisation or operation (Figure 2). Grouped under "grazing practices", the next most common topic, were practices such as cell/paddock design, water systems, fencing, grazing/recovery periods, stock density, calculating forage dry matter availability, and many other topics. Planning-for example, financial planning or the use of grazing charts to plan the animals' rotation throughout the year-was discussed by a little fewer than half of the trainers.

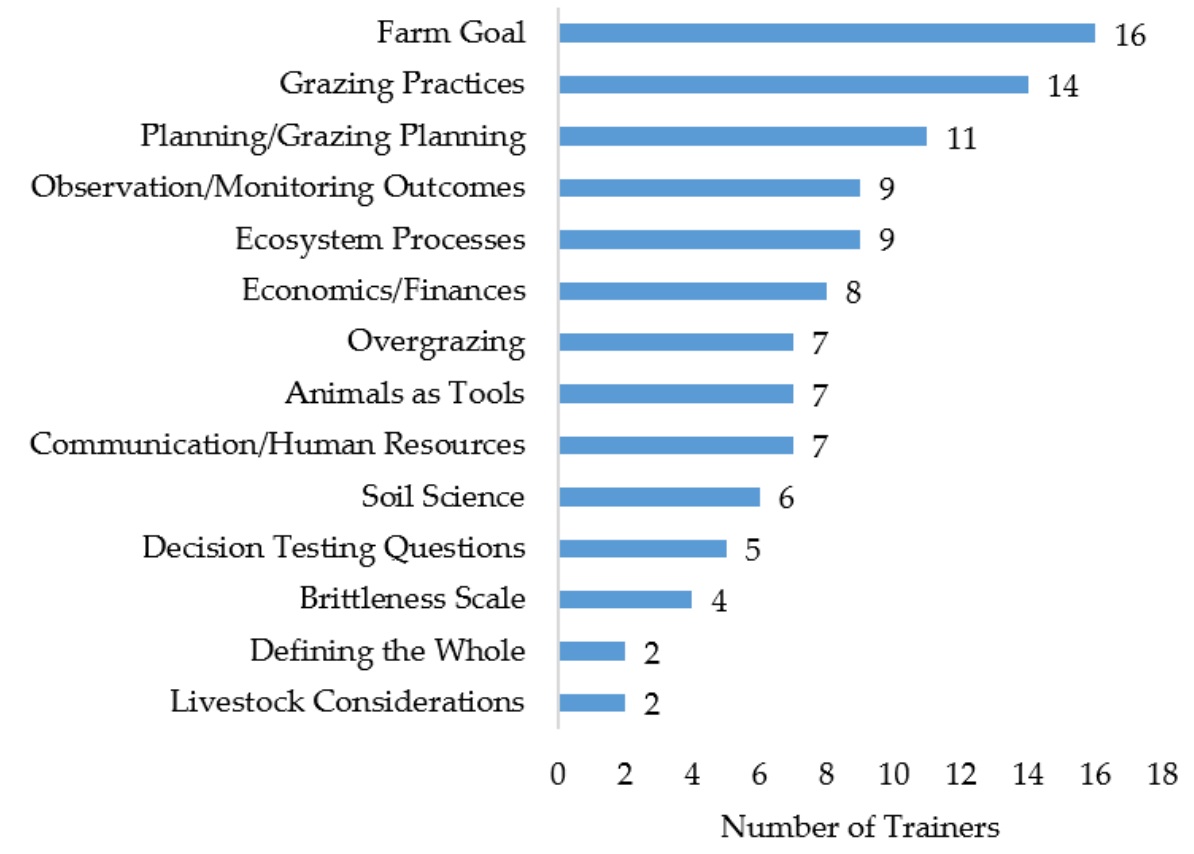

Figure 2. Key themes of adaptive grazing training at the concept/skill level, as mentioned by trainers.

\subsection{The Trainees}

Most adaptive grazing trainees of the interviewed trainers are farmers, with trainers' estimates of this ranging from $50 \%$ to $99 \%$. Some trainers dealt with majority ranchers, including livestock such as cattle, cow-calf, dairy, bison, elk, goats, sheep, chickens and pigs. Others worked with a wider range of farmers: mixed operations, grain farmers, greenhouse operations, organic farmers, vegetable/flower producers, homesteaders and new or prospective farmers. Trainee operations ranged in size from very small ( 5 acres or less) to very large (40,000 acres). Non-farmer participants included extension agents, land agencies, non-profit organisations, consultants, nature conservancies, tribal councils, contract graziers, and occasionally non-agricultural businesses of other kinds.

Most trainers (16) had an approximately equal mix of men and women in their courses, while seven taught mostly men and two taught women-only courses. While they also worked with individuals, most trainers (19) encouraged families, couples or teams to take the training together, and five mentioned offering discounts for multiple attendees from the same organisation/family. Trainees were of all ages, and several trainers mentioned that trainees were getting younger on average. Although we did not specifically ask about race or ethnicity, one trainer volunteered that their classes were majority white (estimated at 95\%), and a second trainer mentioned occasionally working with Native American groups.

Several trainers discussed how the people taking the training affected the quality of the teaching and the discussions. Diversity of trainees had an effect:

"the richness of new ways of doing things, the new ways to think about things, comes from diversity

... So, if you get a bunch of cowboys that think the same way, you know, you're going to get the same result" (US11)

The ratio of men to women in the course also affected the conversations: 
"School's always more interesting when there's women because guys tend to be stupider when they're among themselves, women tend to hold them accountable" (US10)

"[the participants] really liked that it was just women, you know, that creates a certain camaraderie and safe space and, you know, all the good things that can happen when you get a group of women in a room" (US04)

Trainers postulated that people take the training for a wide range of reasons (Figure 3). The most common reasons reported were: to improve finances or production practices for profitability ( 15 trainers) or to improve land health (10 trainers). Nine trainers identified crisis or desperation as a driving factor for individuals, where the training was seen as a last resort for saving the farm: " ... out of desperation, when they're in trouble, when things are really crashing down. They're grasping for something" (US06).

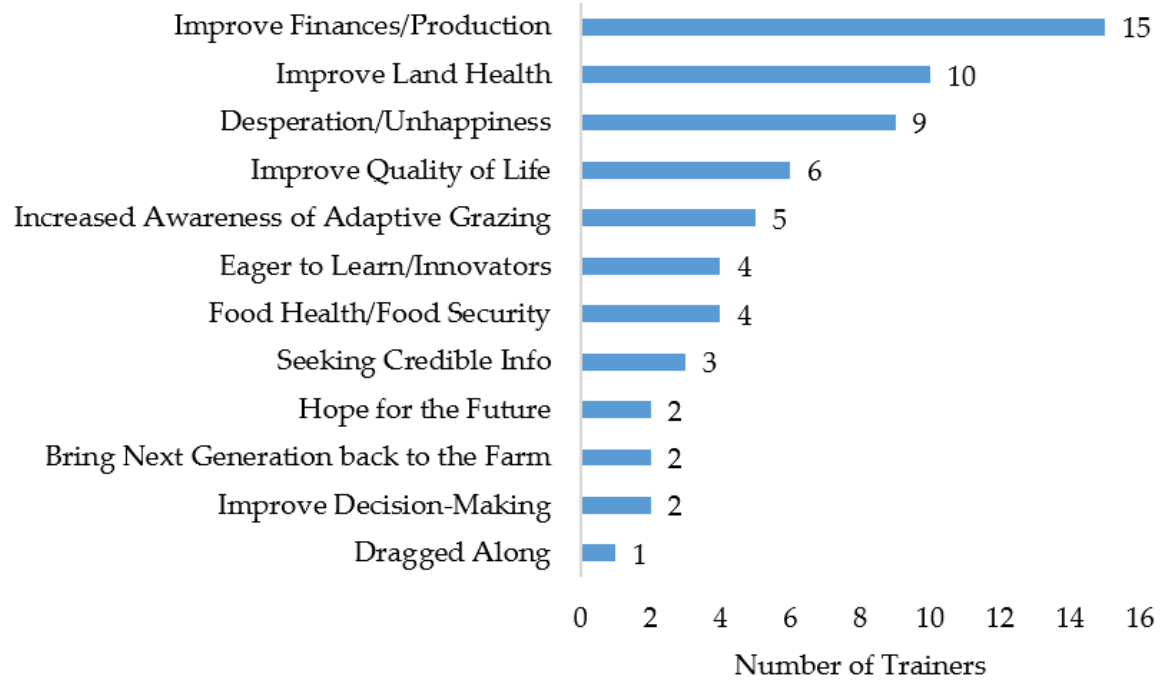

Figure 3. Trainers' perceptions about why people take adaptive grazing training.

Four trainers differentiated between men and women in perceived reasons for trainees undertaking the training. Women were seen to take the training for health reasons-the health of their land, their family or the food that they produce-and for quality of life. As one trainer put it, "The women signed up for the course because they'd never even heard of quality of life before and they sure wanted some" (CA02). For men, the main driver was seen by trainers as improving production practices and profitability. Some trainers perceived women as encouraging their husbands to take the training.

\subsection{Learning}

Trainers were divided on whether trainees were already familiar with adaptive or holistic concepts when they started the training: five said that most were familiar with the concepts, while an equal number said that most were not; a further nine said there was an approximate 50/50 split between those familiar and those not. Four trainers thought that participants were more familiar with the concepts than several decades ago, which they attributed to increased general awareness of adaptive grazing. Three trainers said that participants perceived themselves as being familiar with the concepts of adaptive grazing, but in fact had some misconceptions.

Most trainers (19) perceived trainees to struggle with the concepts they taught. The biggest challenge, identified by 14 trainers, was the requisite paradigm shifts in how they view the world, their operation or themselves (Figure 4): “it's not learning the new thing that's hard, it's letting go of the old thing that's hard" (US10). Seven trainers did not perceive the trainees to struggle with the concepts once the course was underway; however, three of these qualified their statements by saying that the practical application of the concepts on their own operation was difficult: "grasping and practicing are 
two different things, you know" (CA07). This challenge of application at home was the second most common struggle, mentioned by 10 trainers overall. For instance, " ... some folks get home and they're overwhelmed with, okay, you know, how can I apply what I've learned, and some people end up overwhelmed enough that they do- they don't do anything" (US16).

Some of the challenges of application are physical as well as cognitive. One trainer illustrated the issue thus:

"... if you've got a federal grazing lease, and it's tens of thousands of acres, and you're suggesting that they've got to go move the animals frequently, that means that they have to saddle up ... go out and beat the heck out of ... a dusty hot day, and by the time they're finished with that day they've got half, or you know, say three quarters of the animals moved ... Okay, and that was just one day... and if you're talking about moving a couple times a week, you know, you're out of your mind" (US11)

We did not explicitly ask about pedagogical methods the trainers used, but some volunteered the value of certain strategies to overcome these challenges. This trainer, for example, went on to describe parts of his training designed to deal with practical challenges, to make it more feasible on-farm. He encouraged trainees to share things that had worked for them, such as training animals to move by whistle to reduce human labour requirements. As discussed above, nine trainers felt it important to empower their trainees to own the information and see themselves as experts. Many found that demonstration was key:

"... one of the tenets is moving your livestock at least once every day, okay. And initially most people their first impression is, oh my God, impossible, can't do that, takes way too much time, way too much labour, too much cost, are you kidding me? You're asking me to add that much to what I already have to do on a day-to-day basis? But when we take them out into the field and show them just how easy this is to do, you know, you can move a thousand head, building the paddock and moving them, in fifteen minutes, a thousand head" (US09)

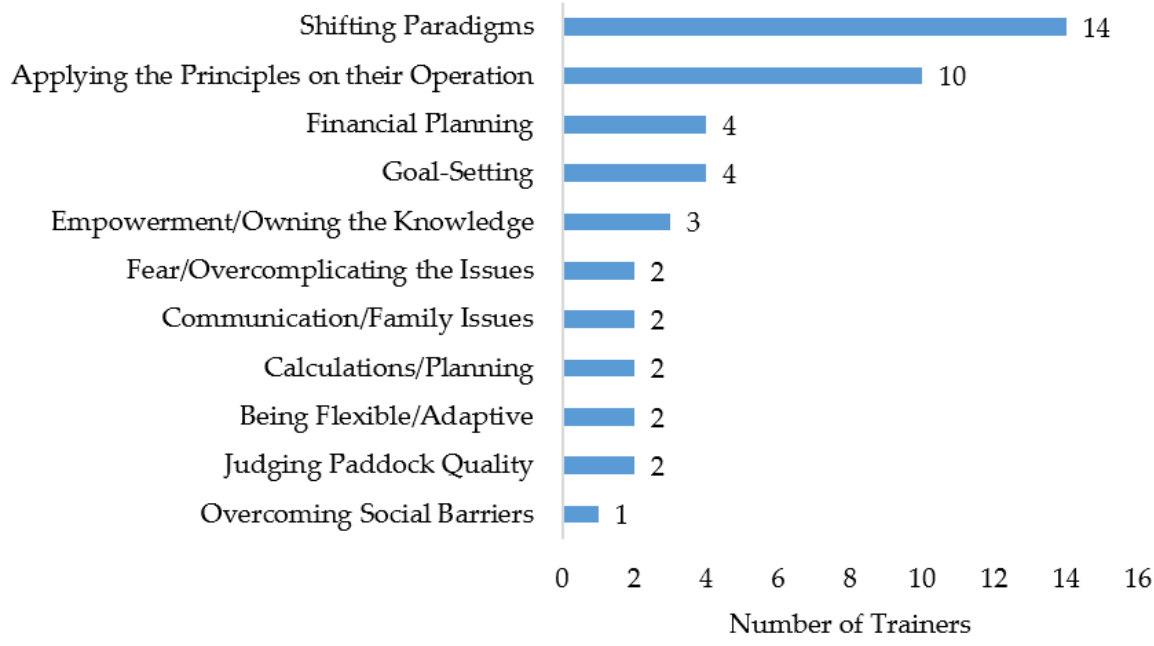

Figure 4. Trainers' perceptions of the concepts that trainees struggle with in adaptive grazing training.

Concepts that trainers perceived trainees to understand more readily included overgrazing, managing animals, and decision-testing questions. One trainer mentioned that the "easy" part of the training was different for each person, and related to their reasons for taking the course:

“... [if] I've got young kids, I want to spend [time with] them-and when I'm on machinery all the time the kids can't help me but if I got to walk out to the pasture and get the cows ... the kids can go with me ... there's usually some hook that's got them interested" (US02) 


\subsection{Adoption}

Most trainers (20) followed up with or kept track of their trainees to some extent, often informally or periodically. Although trainers did not always specify the exact nature of their follow up, two mentioned creating specific member-only groups, either online or in-person, to support former trainees and build community. More commonly, trainers set up Facebook groups, sent out newsletter updates by email, or conducted small surveys of their past trainees. Of the five who did not conduct any follow up, two saw this as a shortcoming in their work and hoped to improve.

When asked about trainee adoption rates, 12 trainers brought up the challenge of defining "adoption" in the context of adaptive grazing. Trainees might adopt some ideas or practices but not others, depending on their abilities and needs, or may adopt at different speeds. To what level must an individual adopt the practices to be considered "adaptive"? Some trainers encouraged partial adoption amongst trainees, either hoping people would take what they needed from the course or recognizing that even partial adoption could be beneficial. For example:

"So while you might look at it and say well, gee, these people really benefited because they did A, B, C, somebody else might've not made a big change, but they got the change that they needed. So I'm a strong believer that everybody benefits depending where they are in their life, what they need, they take what they need out of the course" (CA08)

Others set a more stringent threshold for adoption because holism is such a central concept to adaptive grazing; in other words, being "partially holistic" is not an option:

"the word holistic assumes that you're managing the whole enchilada simultaneously, as imperfect as you may be doing it, managing the whole enchilada imperfectly is going to be hands down [better than] managing parts of it perfectly" (US06)

This issue complicated the question of adoption rates, and estimates varied widely. Some trainers could not even guess; other estimates ranged from "very low" $(<5 \%)$ to "very high" (90-100\%), and everything in between.

The dominant perceived reason for non-adoption, identified by 10 trainers, was social or community pressure on the trainee (Figure 5). Trainers talked about the need for family and community support of the new ideas:

"when you're in a small town ... if you start thinking differently you kind of start to lose your community, and we're human beings, we must have community, and so people after awhile just quit doing it" (CA02)

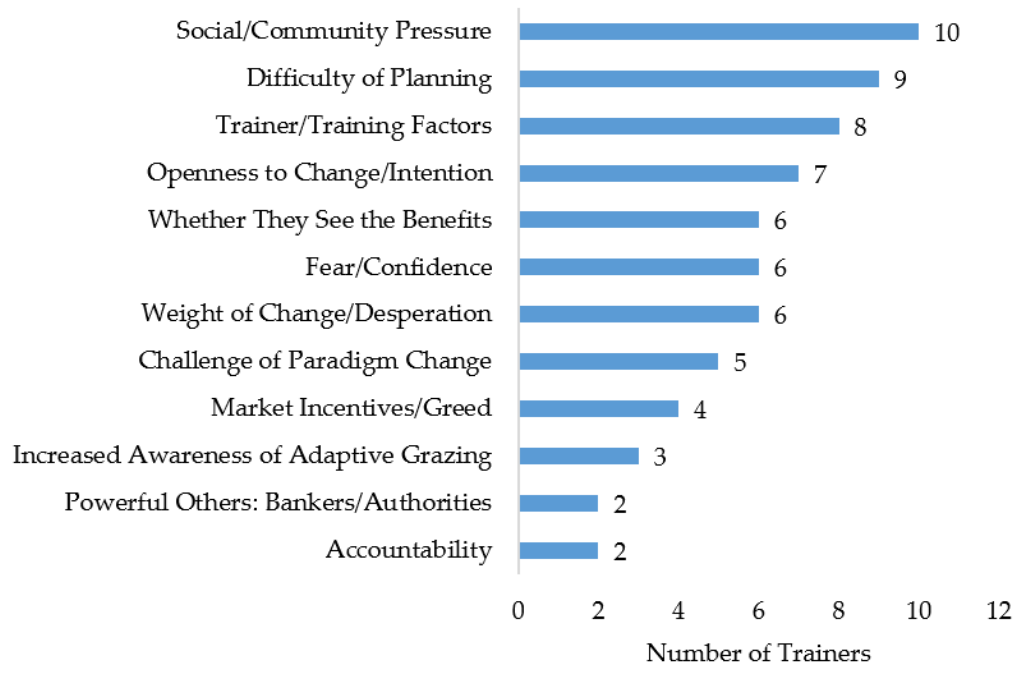

Figure 5. Trainers' perceptions of trainees' reasons for not adopting adaptive grazing practices. 
The second most common factor limiting adoption, mentioned by nine trainers, was the intensive planning required by adaptive grazing, which requires more mental work, more time and more responsibility:

"you can make way more money sitting at your kitchen table planning stuff than you can out in the field, but everybody'd rather be out in the field" (CA02)

"there's a lot of managerial decisions and a lot of people don't want to put that much effort into it.

Don't want to be responsible. Just tell me what to do" (US02)

Trainers also mentioned aspects of their training employed to increase adoption rates: ensuring multiple interactions between trainees and trainers over a longer period of time; building community between like-minded peers; encouraging trainees to apply the concepts that work for them; and being adaptive in the training, to deal with trainees' needs. Several trainers felt that their legitimacy rested on their own identity as producers applying these methods, and they often brought in other producers as teachers as well.

\section{Discussion}

We set out in this work to explore Holistic Management and adaptive grazing from the perspective of the trainer: to understand how they practiced their work and conceived of its impact. Through 25 interviews with trainers across Canada and the US a picture emerges of a heterogeneous field, where trainers hold sometimes congruent, sometimes opposing views about adaptive grazing practices, the people that undertake the training, and adoption rates of the practices. It is important to see this work as a first step into an underdeveloped domain: it is largely descriptive, and unable to be generalized beyond our participants, even with such a relatively homogenous group. As all such exploratory work, it seeks to propose questions rather than answer them or generate theory. Three major themes have emerged to which we can begin to speak, and propose additional work.

\subsection{Fluidity and Adoption of the Adaptive Grazing Concept}

The sheer number of terms for $\mathrm{HM}$ or similar grazing strategies (Box 1) underlines the difficulty of defining and assessing the practice. This web of appellations is complicated by sometimes contradictory definitions, used even by adaptive grazing trainers themselves: four HM-aligned trainers did not consider their training to fully align with HM principles, while two non-HM trainers did. The "non-conforming" HM-trainers used different training styles or were less stringent in their directives to trainees, which raises a question: what really constitutes an adaptive farmer or HM-practitioner?

Every trainer considered decision-making to be a critical component of their work-in fact, $30 \%$ said that their training focused mainly on decision-making rather than practical ranching or farming skills. Although many trainers worked primarily with ranchers, most also worked with a minority of non-ranchers, including other types of farmers, extension agents, conservationists and even non-agricultural businesses. Two trainers did not work with ranchers at all. Taken together, these findings indicate that HM is more than just a grazing strategy: like permaculture [61], the principles of holistic thinking and decision-making can be applied in many non-grazing situations, and Savory has also made this argument [28]. To our knowledge, however, the efficacy of HM has only been assessed in grazing contexts and has not been extended to explore HM in other types of farming or to other "wholes" under management.

Much of the experimental research purporting to assess HM experimentally ignores this significant decision-making factor and the role of the land manager [14]. For instance, Briske et al. [55] failed to acknowledge HM's significant social and decision-making components when they attempted to use evidence from experimental controlled grazing to discredit social science about HM. Savory is critical of experimental HM research on this basis [28,41]. Evidently, HM or adaptive grazing means 
different things to different people, although this is muddy in research purporting to assess HM or similar strategies. Academic research typically forces distinct categories so that comparisons can be made, whereas our findings indicate that, in reality, there is a diverse continuum of principles and practices that are applied to varying degrees in wide-ranging contexts.

Discussion with trainers around the adoption rates of adaptive grazing was complicated by the issue of definition: did farmers need to fully commit to adaptive grazing principles to be considered "adaptive"? This is a site of great tension within our data. While some trainers thought that one must be "wholly holistic", others encouraged their trainees to choose and apply the concepts that were most useful for them. Some trainers, in turn, seemed to be adapting Savory's principles for their practice in ways some felt he may not endorse, and accordingly they varied in how closely they identified or aligned with Savory and HM. The decision-making principles are more widely applicable than the grazing methods to the wide range of trainees that trainers work with, so perhaps it is not surprising that the grazing method and decision-making skills were separated by trainers: it increases their potential pool of trainees and thus impact. Is this clever marketing or a more substantial emerging difference in how HM and adaptive grazing are theorized, and how they are taught and practiced? Perhaps from working with a wide range of trainees and in diverse contexts, some trainers have found a benefit in improving decision-making with systems and adaptive thinking, irrespective of the grazing methods used. Their search for new terms to describe their approach has likely contributed to some of the fragmentation of language we saw when recruiting trainers (see also Sherren and Kent [17]). These differing approaches and identities, which may vary in their outcomes, call for more in-depth research.

Adoption of HM practices has been estimated at 5-10\% across a range of jurisdictions [34]. Ranchers choose grazing management strategies that they believe will bring them toward their long-term goals with lowest risk and highest flexibility [31]. The perception of the usefulness of any practice is affected by the learning experience, the social characteristics and circumstances of the individual, and the features of the practice itself [62]. It is difficult to apply a standard adoption model to sustainable agriculture methods because most do not fit the requirements of being easy to adopt, understandable, low-risk and compatible with local norms [63]. Adaptive grazing is no different: because of its holistic nature, it cannot be easily trialed, it requires significant training and input of time and energy, and it represents a sharp break from traditional values and practices. That the significant planning and monitoring are barriers to adoption has been identified by past research [37].

Community pressures were also identified by trainers as key barriers to adaptive grazing uptake. In response to perceptions that trainees are fearful of their neighbours' reactions, some trainers discussed the importance of connecting trainees with like-minded peers in their area, and the majority conducted follow-ups to maintain connections. Research indicates that HM producers enjoy stronger social network cohesion than non-HM producers [36], despite, or perhaps because of, the general lack of readily available peers-in-practice nearby. Similarly, early adopters of organic farming typically have more social connections outside of their community, meaning they are likely less dependent on social acceptance within the local farming community [63]. The transition from one community to the other may be challenging and risky for the individual. Because conventional grazing remains dominant in rangeland regions, conventional farmers can draw on more extensive social resources while HM farmers become outsiders [64].

\subsection{Paradigm Shifts and Holism}

Systems thinking requires a shift in mental paradigms from reductionist to integrated, holistic thought. Meadows [44] identified paradigms—-shifting, or even transcending paradigms—as the strongest leverage points for creating system change; these are also the most challenging strategies. Adopting systems thinking in agriculture is difficult because it requires individuals to break radically from the status quo and question their own beliefs [20]. Savory's "religious zeal" [17,29] hints at this radical, paradigm-level shift in perception, and though our data do not support exploration of religious 
zeal amongst trainers, this would be a worthwhile topic for future research. Paradigm shifts have previously been identified as a key barrier to adaptive grazing uptake by HM practitioners [37], which was mirrored in the trainer interviews.

Paradigm-level lessons were a key component of adaptive grazing training, and the difficulty of changing paradigms was identified as the main barrier to adaptive grazing adoption. Paradigm-level lessons focused around four areas: holism, complexity, empowerment and mimicking nature. The dichotomy of paradigm-level versus concept/skill-level training to some extent mirrors agroecology, which has been framed as a science, a movement and a practice [65]. Although at present the science of HM is contested, the HM movement parallels what we have termed the paradigm shift-the big picture ideas about "what it means to be HM" and "who we are as HM-practitioners". Similarly, the concepts and skills taught in HM training carry out those ideals on farm-the practice.

Paradigm-level differences have previously been identified between conventional and alternative farmers in Canada [66]. Conventional producers generally believed humans to exist outside of and above natural processes, whereas alternative producers believed themselves to be more fully integrated into the ecosystem and subscribed to "ecocentric" views [66]. This has been referred to as the "command and control" paradigm in conventional agriculture [67]. Future research could explore paradigm differences between HM and non-HM "trainers", such as extension agents, to provide further context for this discussion. Mental paradigms are clearly a key component of adopting sustainable farming practices, but whether those paradigm differences catalyze adoption of sustainable practices or vice versa remains unclear. A question lingers: can one be trained into systems thinking, and its application, or is this something born?

\subsection{Adaptive Grazing and Gender}

Trainers perceived gender differences in terms of why men and women take the training and how gender composition affects the training itself. Women were perceived to take the training for health reasons and for quality of life, whereas men were perceived to be more interested in profitability and production. Women also play a pivotal role in organic farming uptake because organic methods can be trialed in the kitchen garden, which is traditionally the woman's domain, and because women may be more driven by family health concerns [63]. This may support the perception of some trainers that some men took the training because their wives urged them to.

Alternately, it may indicate that the more labour-intensive HM approach requires both partners in a marriage to be actively farming, instead of just one. In Australia, HM farms were more likely to involve both husband and wife in management decisions, as well as social science interviews, whereas on non-HM farms, the wife was more likely to have off-farm employment [34]. Off-farm employment balanced out the highs and lows of conventional farming; the HM producers had more predictable moderate income, but this required higher stakes and thus more careful decision-making. Abson et al. [64] suggested that conventional farms build resilience to environmental perturbations through financial capital, using the higher profits from good years to pay for increased costs in lean years, such as buying off-farm feed. On the other hand, HM internalizes resiliency by building natural capital in the farm ecosystem [64]; having both members of a couple work full-time on the farm underlines this "all in" aspect of HM-farming.

During adaptive grazing training, two trainers perceived that having a diverse mix of men and women positively influenced the course-bringing in a mix of ideas, in one case, or keeping the men on track, in the other-but one trainer who taught a women-only course discussed the positive camaraderie and strengthened relationships that resulted. Systems thinking has indicated that men generally perform better than women in simulated complex tasks, perhaps because men have higher self-rating of skills $[68,69]$ or because their riskier behaviour in simulation games allows them to explore the system structure more deeply [70]. However, a key weakness of much systems thinking research is its focus on the individual, whereas most real-world decisions are made by teams of people with a variety of skills and risk-aversity [70]. Because many farms are run by families and teams, more 
research assessing group systems thinking skills, particularly with respect to teams of mixed genders, may provide deeper insights into this question.

\section{Conclusions}

Adaptive grazing is one approach to applying systems thinking to agricultural systems. Although the methods and outcomes of specific methods such as HM remain controversial, researchers from both sides of the dialogue have indicated that its emphasis on holism and adaptivity may make it a valuable tool for helping farmers deal with complexity. Adaptive grazing training combines lessons on day-to-day skills and concepts with paradigm-level shifts in understanding. Holism is the major theme throughout these lessons, such that trainees are asked to shift not only their management practices-for example, by incorporating a holistic farm goal—but also to change their entire worldview. Trainees struggle with these paradigm shifts, as well as struggle with applying the concepts to their own operation. The biggest barrier to adoption was perceived as social or community pressure to maintain the status quo, which is reflected in other studies on alternative farming practices.

Adaptive grazing remains a fringe practice in the ranching community. Lack of experimental evidence to support some of Savory's more controversial grazing claims make it difficult to fully endorse the system. In practice, trainers struggled with defining HM adoption and felt that the holistic and adaptive decision-making components of the training could be completely separated from the practical grazing lessons, and may even be more important. Combined with the finding that some trainers taught HM principles in non-grazing situations, $\mathrm{HM}$ is a surprisingly heterogeneous concept, which makes defining and assessing the system difficult. This study forms the basis for future research on HM in practice, which should explore the significant decision-making and systems thinking components both within and beyond grazing applications.

Author Contributions: C.M. and K.S. conceived and designed the study; C.M. performed the data collection and analysis; and C.M. and K.S. wrote the paper.

Acknowledgments: This research was funded by a Social Sciences and Humanities Research Council of Canada Insight Grant to KS (\#435-2015-0702, 2015-2019).

Conflicts of Interest: The authors declare no conflict of interest.

\section{References}

1. Tubiello, F.N.; Salvatore, M.; Ferrara, A.F.; House, J.; Federici, S.; Rossi, S.; Biancalani, R.; Condor Golec, R.D.; Jacobs, H.; Flammini, A.; et al. The Contribution of Agriculture, Forestry and other Land Use activities to Global Warming, 1990-2012. Glob. Chang. Biol. 2015, 21, 2655-2660. [CrossRef] [PubMed]

2. Beck, J. Predicting climate change effects on agriculture from ecological niche modeling: Who profits, who loses? Clim. Chang. 2013, 116, 177-189. [CrossRef]

3. Motha, R.; Baier, W. Impacts of Present and Future Climate Change and Climate Variability on Agriculture in the Temperate Regions: North America. Clim. Chang. 2005, 70, 137-164. [CrossRef]

4. UNCCD Is Desertification a Global Problem? Available online: https://www2.unccd.int/frequently-askedquestions-faq (accessed on 11 September 2017).

5. Scholes, R.; Montanarella, L.; Brainich, A.; Barger, N.; ten Brink, B.; Cantele, M.; Erasmus, B.; Fisher, J.; Gardner, T.; Holland, T.G.; et al. Summary for Policymakers of the Thematic assessment Report on Land Degradation and Restoration of the Intergovernmental Science-Policy Platform on Biodiversity and Ecosystem Services; IPBES Secretariat: Bonn, Germany, 2018; pp. 1-31.

6. Smith, P.; House, J.I.; Bustamante, M.; Sobocka, J.; Harper, R.; Pan, G.; West, P.C.; Clark, J.M.; Adhya, T.; Rumpel, C.; et al. Global change pressures on soils from land use and management. Glob. Chang. Biol. 2016, 22, 1008-1028. [CrossRef] [PubMed]

7. Foley, J.A.; Defries, R.; Asner, G.P.; Barford, C.; Bonan, G.; Carpenter, S.R.; Chapin, F.S.; Coe, M.T.; Daily, G.C.; Gibbs, H.K.; et al. Global consequences of land use. Science 2005, 309, 570-574. [CrossRef] [PubMed] 
8. Godfray, H.C.; Beddington, J.R.; Crute, I.R.; Haddad, L.; Lawrence, D.; Muir, J.F.; Pretty, J.; Robinson, S.; Thomas, S.M.; Toulmin, C. Food security: The challenge of feeding 9 billion people. Science 2010, 327, 812-818. [CrossRef] [PubMed]

9. Asner, G.; Elmore, A.; Olander, L.; Martin, R.; Harris, A. Grazing Systems, Ecosystem Responses, and Global Change. Annu. Rev. Environ. Resour. 2004, 29, 261-299. [CrossRef]

10. Steinfeld, H.; Gerber, P.; Wassenaar, T.; Castel, V.; De Haan, C. Livestock's Long Shadow: Environmental Issues and Options; Food and Agriculture Organization: Rome, Italy, 2006.

11. Goodland, R.; Anhang, J. Livestock and climate change. World Watch 2009, 22, 10-19.

12. Stanley, P.L.; Rowntree, J.E.; Beede, D.K.; DeLonge, M.S.; Hamm, M.W. Impacts of soil carbon sequestration on life cycle greenhouse gas emissions in Midwestern USA beef finishing systems. Agric. Syst. 2018, 162, 249-258. [CrossRef]

13. Savory, A. How to Fight Desertification and Reverse Climate Change; The World Bank Group: Washington, DC, USA, 2013.

14. Nordborg, M.; Röös, E. Holistic Management-A Critical Review of Allan Savory's Grazing Method; SLU/EPOK -Centre for Organic Food \& Farming \& Chalmers: Uppsala, Sweden, 2016.

15. Briske, D.D.; Bestelmeyer, B.T.; Brown, J.R.; Fuhlendorf, S.D.; Wayne Polley, H. The Savory Method Can Not Green Deserts or Reverse Climate Change: A response to the Allan Savory TED video: A response to the Allan Savory TED video. Rangelands 2013, 35, 72-74. [CrossRef]

16. Carter, J.; Jones, A.; O’brien, M.; Ratner, J.; Wuerthner, G. Holistic Management: Misinformation on the Science of Grazed Ecosystems. Int. J. Biodivers. 2014, 2014. [CrossRef]

17. Sherren, K.; Kent, C. Who's afraid of Allan Savory? Scientometric polarization on Holistic Management as competing understandings. Renew. Agric. Food Syst. 2017, 1-16. [CrossRef]

18. Briske, D.D.; Derner, J.D.; Brown, J.R.; Fuhlendorf, S.D.; Teague, W.R.; Havstad, K.M.; Gillen, R.L.; Ash, A.J.; Willms, W.D. Rotational Grazing on Rangelands: Reconciliation of Perception and Experimental Evidence. Rangel. Ecol. Manag. 2008, 61, 3-17. [CrossRef]

19. Briske, D.D.; Sayre, N.F.; Huntsinger, L.; Fernandez-Gimenez, M.; Budd, B.; Derner, J.D. Origin, Persistence, and Resolution of the Rotational Grazing Debate: Integrating Human Dimensions Into Rangeland Research. Rangel. Ecol. Manag. 2011, 64, 325-334. [CrossRef]

20. Bawden, R. Systems Thinking and Practice in Agriculture. J. Dairy Sci. 1991, 74, 2362-2373. [CrossRef]

21. Bosch, O.J.H.; King, C.A.; Herbohn, J.L.; Russell, I.W.; Smith, C.S. Getting the big picture in natural resource management-Systems thinking as 'method' for scientists, policy makers and other stakeholders. Syst. Res. Behav. Sci. 2007, 24, 217-232. [CrossRef]

22. Mingers, J.; White, L. A review of the recent contribution of systems thinking to operational research and management science. Eur. J. Oper. Res. 2010, 207, 1147-1161. [CrossRef]

23. Mitchell, J.; Harben, R.; Sposito, G.; Shrestha, A.; Munk, D.; Miyao, G.; Southard, R.; Ferris, H.; Horwath, W.; Kueneman, E. Conservation agriculture: Systems thinking for sustainable farming. Calif. Agric. 2016, 70, 53-56. [CrossRef]

24. Hodbod, J.; Barreteau, O.; Allen, C.; Magda, D. Managing adaptively for multifunctionality in agricultural systems. J. Environ. Manag. 2016, 183, 379-388. [CrossRef] [PubMed]

25. Öllinger, M.; Hammon, S.; von Grundherr, M.; Funke, J. Does visualization enhance complex problem solving? The effect of causal mapping on performance in the computer-based microworld Tailorshop. Educ. Technol. Res. Dev. 2015, 63, 621-637. [CrossRef]

26. Doyle, J. The cognitive psychology of systems thinking. Syst. Dyn. Rev. 1997, 13, 253-265. [CrossRef]

27. Voisin, A. Grass Productivity; Island Press: Washington, DC, USA, 1988.

28. Savory, A. Holistic Management: A Commonsense Revolution to Restore Our Environment; Island Press: Washington, DC, USA, 2016.

29. Chiaviello, A. Anarchy in range science: Allan Savory and the rhetoric of holistic resource management. In Technical Communication, Deliberative Rhetoric, and Environmental Discourse: Connections and Directions; Ablex Publishing Corporation: Stamford, CT, USA, 2000; pp. 301-320.

30. Holechek, J.L.; Valdez, R. Short-Duration Grazing: The Facts in 1999. Rangelands 2000, 22, 18-22. [CrossRef]

31. Wilmer, H.; Augustine, D.J.; Derner, J.D.; Fernández-Giménez, M.E.; Briske, D.D.; Roche, L.M.; Tate, K.W.; Miller, K.E. Diverse Management Strategies Produce Similar Ecological Outcomes on Ranches in Western Great Plains: Social-Ecological Assessment. Rangel. Ecol. Manag. 2017, in press. [CrossRef] 
32. Hawkins, H. A global assessment of Holistic Planned Grazing ${ }^{\mathrm{TM}}$ compared with season-long, continuous grazing: Meta-analysis findings. Afr. J. Range Forage Sci. 2017, 34, 65-75. [CrossRef]

33. Jakoby, O.; Quaas, M.F.; Baumgärtner, S.; Frank, K. Adapting livestock management to spatio-temporal heterogeneity in semi-arid rangelands. J. Environ. Manag. 2015, 162, 179-189. [CrossRef] [PubMed]

34. Sherren, K.; Fischer, J.; Fazey, I. Managing the grazing landscape: Insights for agricultural adaptation from a mid- drought photo- elicitation study in the Australian sheep-wheat belt. Agric. Syst. 2012, 106, 72-83. [CrossRef]

35. Bohnet, I.C.; Roberts, B.; Harding, E.; Haug, K.J. A typology of graziers to inform a more targeted approach for developing natural resource management policies and agricultural extension programs. Land Use Policy 2011, 28, 629-637. [CrossRef]

36. De Villiers, A.; Esler, K.; Knight, A. Social processes promoting the adaptive capacity of rangeland managers to achieve resilience in the Karoo, South Africa. J. Environ. Manag. 2014, 146, 276-283. [CrossRef] [PubMed]

37. Stinner, D.H.; Stinner, B.R.; Martsolf, E. Biodiversity as an organizing principle in agroecosystem management: Case studies of holistic resource management practitioners in the USA. Agric. Ecosyst. Environ. 1997, 62, 199-213. [CrossRef]

38. Roche, L.M.; Cutts, B.B.; Derner, J.D.; Lubell, M.N.; Tate, K.W. On-Ranch Grazing Strategies: Context for the Rotational Grazing Dilemma. Rangel. Ecol. Manag. 2015, 68, 248-256. [CrossRef]

39. Sherren, K.; Darnhofer, I. Precondition for Integration: In Support of Stand-alone Social Science in Rangeland and Silvopastoral Research. Rangel. Ecol. Manag. 2017, in press. [CrossRef]

40. LaCanne, C.E.; Lundgren, J.G. Regenerative agriculture: Merging farming and natural resource conservation profitably. PeerJ 2018, 6, e4428. [CrossRef] [PubMed]

41. Savory, A. Response to Request for Information on the "Science" and "Methodology" Underpinning Holistic Management and Holistic Planned Grazing; Savory Institute: Strasburg, CO, USA, 2013; Available online: http:/ / www.savoryinstitute.com (accessed on 25 August 2017).

42. Sweeney, L.B.; Sterman, J.D. Bathtub dynamics: Initial results of a systems thinking inventory. Syst. Dyn. Rev. 2000, 16, 249-286. [CrossRef]

43. Villamor, G.; Badmos, B. Grazing game: A learning tool for adaptive management in response to climate variability in semiarid areas of Ghana. Ecol. Soc. 2016, 21. [CrossRef]

44. Meadows, D.H. Thinking in Systems: A Primer; Chelsea Green Publishing: Hartford, VT, USA, 2008.

45. Bennet, A.; Bennet, D. The Decision-Making Process in a Complex Situation. In Handbook on Decision Support Systems 1; Springer: Berlin, Germany, 2008; pp. 3-20.

46. Schiere, J.; Groenland, R.; Vlug, A.; Van Keulen, H. System thinking in agriculture: An overview. In Emerging Challenges for Farming Systems-Lessons from Australian and Dutch Agriculture; Rickert, K., Ed.; Rural Industries Research and Development Corporation: Kingston, UK, 2004.

47. Sterman, J.D. Learning in and about complex systems. Syst. Dyn. Rev. 1994, 10, 291-330. [CrossRef]

48. Bland, W.L.; Bell, M.M. A holon approach to agroecology. Int. J. Agric. Sustain. 2007, 5, 280-294.

49. Wezel, A.; Soldat, V. A quantitative and qualitative historical analysis of the scientific discipline of agroecology. Int. J. Agric. Sustain. 2009, 7, 3-18. [CrossRef]

50. Ruiz-Rosado, O. Agroecology: A discipline leading towards transdiscipline. Interciencia 2006, 31, 140-145.

51. Klerkx, L.; Aarts, N.; Leeuwis, C. Adaptive management in agricultural innovation systems: The interactions between innovation networks and their environment. Agric. Syst. 2010, 103, 390-400. [CrossRef]

52. Spielman, D.J. Innovation Systems Perspectives on Developing-Country Agriculture: A Critical Review; International Food Policy Research Institute: Washington, DC, USA, 2005.

53. King, C.A. Community resilience and contemporary agri-ecological systems: Reconnecting people and food, and people with people. Syst. Res. Behav. Sci. 2008, 25, 111-124. [CrossRef]

54. Kheel, M. Nature Ethics: An Ecofeminist Perspective; Rowman \& Littlefield Publishers: Lanham, MD, USA, 2007.

55. Briske, D.D.; Ash, A.J.; Derner, J.D.; Huntsinger, L. Commentary: A critical assessment of the policy endorsement for holistic management. Agric. Syst. 2014, 125, 50-53. [CrossRef]

56. Garbach, K.; Milder, J.C.; DeClerck, F.A.; de Wit, M.M.; Driscoll, L.; Gemmill-Herren, B. Examining multi-functionality for crop yield and ecosystem services in five systems of agroecological intensification. Int. J. Agric. Sustain. 2017, 15, 11-28. [CrossRef] 
57. Savory, A. Holistic Management: Presentation at South Dakota State University and the South Dakota Grassland Coalition, South Dakota. 2014. Available online: https://www.youtube.com/watch?v= kvpeLFrk5io (accessed on 17 January 2018).

58. Kestin, H.D. Qualitative Research in Action: A Canadian Primer; Oxford University Press Canada: Don Mills, ON, Canada, 2012.

59. Hsieh, H.; Shannon, S.E. Three approaches to qualitative content analysis. Qual. Health Res. 2005, 15, 1277-1288. [CrossRef] [PubMed]

60. Sandelowski, M. Real qualitative researchers do not count: The use of numbers in qualitative research. Res. Nurs. Health 2001, 24, 230-240. [CrossRef] [PubMed]

61. Mannen, D.; Hinton, S.; Kuijper, T.; Porter, T. Sustainable organizing: A multiparadigm perspective of organizational development and permaculture gardening. J. Leadersh. Organ. Stud. 2012, 19, 355-368. [CrossRef]

62. Pannell, D.J.; Marshall, G.R.; Barr, N.; Curtis, A.; Vanclay, F.; Wilkinson, R. Understanding and promoting adoption of conservation practices by rural landholders. Aust. J. Exp. Agric. 2006, 46, 1407-1424. [CrossRef]

63. Padel, S. Conversion to Organic Farming: A Typical Example of the Diffusion of an Innovation? Sociol. Rural. 2001, 41, 40-61. [CrossRef]

64. Abson, D.J.; Sherren, K.; Fischer, J. The Resilience of Australian Agricultural Landscapes Characterized by Land Sparing versus Land Sharing. In Agricultural Resilience: Perspectives from Ecology and Economics; Gardener, S., Ramsden, S., Hails, R., Eds.; Cambridge University Press: Cambridge, UK, 2014.

65. Wezel, A.; Bellon, S.; Doré, T.; Francis, C.; Vallod, D.; David, C. Agroecology as a science, a movement and a practice. A review. Agron. Sustain. Dev. 2009, 29, 503-515. [CrossRef]

66. Abaidoo, S.; Dickinson, H. Alternative and conventional agricultural paradigms: Evidence from farming in southwest Saskatchewan. Rural Sociol. 2002, 67, 114-131. [CrossRef]

67. Holling, C.S.; Meffe, G.K. Command and control and the pathology of natural resource management. Conserv. Biol. 1996, 10, 328-337. [CrossRef]

68. Bandura, A.; Wood, R. Effect of Perceived Controllability and Performance Standards on Self-Regulation of Complex Decision Making. J. Pers. Soc. Psychol. 1989, 56, 805-814. [CrossRef] [PubMed]

69. Ackerman, P.L.; Kanfer, R.; Goff, M. Cognitive and Noncognitive Determinants and Consequences of Complex Skill Acquisition. J. Exp. Psychol. Appl. 1995, 1, 270-304. [CrossRef]

70. Wittmann, W.; Hattrup, K. The relationship between performance in dynamic systems and intelligence. Syst. Res. Behav. Sci. 2004, 21, 393-409. [CrossRef] 